\title{
Association of epilepsy and asthma: A population-based retrospective cohort study
}

\author{
Kuo-Liang Chiang ${ }^{\text {Corresp.. }}{ }^{1,2,3}{ }^{\text {, Fang-Chuan Kuo }}{ }^{4}$, Jen-Yu Lee ${ }^{5}$, Chin-Yin Huang ${ }^{6}$ \\ 1 Department of Pediatric Neurology, Kuang-Tien General Hospital, Taichung, Taiwan \\ 2 Department of Nutrition, Hungkuang University, Taichung, Taiwan \\ 3 Department of Industrial Engineering and Enterprise Information, Tunghai University, Taichung, Taiwan \\ 4 Department of Physical Therapy, Hungkuang University, Taichung, Taiwan \\ 5 Department of Statistics, Feng Chia University, Taichung, Taiwan \\ 6 Program for Health Administration, Tunghai University, Taichung, Taiwan \\ Corresponding Author: Kuo-Liang Chiang \\ Email address: lambier.tw@yahoo.com.tw
}

Background. Epidemiologic data supporting the epilepsy-asthma association are insufficient. Therefore, we examined this association in this study.

Methods. By using claims data from the National Health Insurance Research Database (Taiwan), we executed a retrospective cohort analysis. Analysis 1 entailed comparing 150,827 patients diagnosed as having incident asthma during 1996-2013 with disease-free controls who were selected randomly during the same period, frequency matched in terms of age and sex. Similarly, analysis 2 entailed comparing 25,274 patients newly diagnosed as having epilepsy with sex- and age-matched controls who were selected randomly. At the end of 2013, we evaluated in analysis 1 the epilepsy incidence and risk and evaluated in analysis 2 the asthma incidence and risk. We applied Kaplan-Meier analysis to derive plots of the proportion of asthma-free seizures.

Results. In analysis 1, the asthma group exhibited a higher epilepsy incidence than did the control group (3.05 versus 2.26 per 1,000 person-years; adjusted hazard ratio: 1.39, 95\% confidence interval: 1.33-1.45). We also noted a greater risk of subsequent epilepsy in women and girls. In analysis 2 , we determined that the asthma incidence between the control and epilepsy groups did not differ significantly; however, some age subgroups including children and individuals in their 30s had an increased risk. A negative association was found in adolescents. The Kaplan-Meier analysis revealed epilepsy to be positively associated with subsequent onset of asthma within 7 years of epilepsy diagnosis.

Discussion. Asthma may be associated with high epilepsy risk, and epilepsy may be associated with high asthma risk among children and individuals in their 30s. Nevertheless, people with epilepsy in other age subgroups should be aware of the possibility of developing asthma within 7 years of epilepsy diagnosis. 
1 Association of epilepsy with asthma: A population-based retrospective cohort study

2 Kuo-Liang Chiang ${ }^{1,2,3, *}$, Fang-Chuan $\mathrm{Kuo}^{4}$, Jen-Yu Lee ${ }^{5,}$ and Chin-Yin Huang ${ }^{6}$

3

$4 \quad{ }^{1}$ Department of Pediatric Neurology, Kuang-Tien General Hospital, Taichung, Taiwan

$5 \quad{ }^{2}$ Department of Nutrition, Hungkuang University, Taichung, Taiwan

$6{ }^{3}$ Department of Industrial Engineering and Enterprise Information, Tunghai University,

7 Taichung, Taiwan

$8{ }^{4}$ Department of Physical Therapy, Hungkuang University, Taichung, Taiwan

$9 \quad{ }^{5}$ Department of Statistics, Feng Chia University, Taichung, Taiwan

10 'Program for Health Administration, Tunghai University, Taichung, Taiwan

11 Corresponding Author:

12 Kuo-Liang Chiang ${ }^{1}$

13 No.117, Shatian Road Shalu District, Taichung City 433, Taiwan

14 E-mail:

$15 *$ These authors contributed equally to this work.

16 Data available statement:

17 Data are available from the National Health Insurance Research Database (NHIRD) published by Taiwan 
18 National Health Insurance (NHI) Bureau. The data utilized in this study cannot be made available in the 19 paper, the supplemental files, or in a public repository due to the "Personal Information Protection Act" 20 executed by Taiwan's government, starting from 2012. Requests for data can be sent as a formal proposal 21 to the NHIRD (http://nhird.nhri.org.tw) or by email to nhird@nhri.org.tw. 
22 ABSTRACT

23 Background. Epidemiologic data supporting the epilepsy-asthma association are insufficient.

24 Therefore, we examined this association in this study.

25 Methods. By using claims data from the National Health Insurance Research Database (Taiwan), 26 we executed a retrospective cohort analysis. Analysis 1 entailed comparing 150,827 patients 27 diagnosed as having incident asthma during 1996-2013 with disease-free controls who were 28 selected randomly during the same period, frequency matched in terms of age and sex. Similarly, analysis 2 entailed comparing 25,274 patients newly diagnosed as having epilepsy with sex- and age-matched controls who were selected randomly. At the end of 2013, we evaluated in analysis 1 the epilepsy incidence and risk and evaluated in analysis 2 the asthma incidence and risk. We applied Kaplan-Meier analysis to derive plots of the proportion of asthma-free seizures.

Results. In analysis 1, the asthma group exhibited a higher epilepsy incidence than did the control group (3.05 versus 2.26 per 1,000 person-years; adjusted hazard ratio: 1.39, 95\% confidence interval: 1.33-1.45). We also noted a greater risk of subsequent epilepsy in women and girls. In analysis 2, we determined that the asthma incidence between the control and epilepsy groups did not differ significantly; however, some age subgroups including children and individuals in their 30 s had an increased risk. A negative association was found in adolescents. The Kaplan-Meier analysis revealed epilepsy to be positively associated with subsequent onset 40 of asthma within 7 years of epilepsy diagnosis.

41 Discussion. Asthma may be associated with high epilepsy risk, and epilepsy may be associated 42 with high asthma risk among children and individuals in their 30s. Nevertheless, people with epilepsy in other age subgroups should be aware of the possibility of developing asthma within 7 
44 years of epilepsy diagnosis. 
46

47

48

49

50

51

52

53

54

55

56

57

58

59

60

61

62

63

64

65

66

67

68

\section{INTRODUCTION}

Asthma and epilepsy are syndromes of heterogeneous diseases with likely multifactorial origins. Epilepsy, a ubiquitous neurological disease, is characterized by the occurrence of convulsive and nonconvulsive seizures. Estimates have revealed that epilepsy affects more than 50 million people worldwide, including 2 million people in the United States (Browne \& Holmes, 2001; Chang \& Lowenstein, 2003), and Moreover, asthma, a ubiquitous chronic disease, inherently involves changing degrees of airflow obstruction and airway inflammation as well as coughing, wheezing, and dyspnea episodes. Asthma has been estimated to affect over 300 million people worldwide, including 20 million people in the United States (Masoli et al., 2004; Olin \& Wechsler, 2014). In Taiwan, the age-adjusted prevalence of epilepsy was 5.85 (per 1000) between 2000 and 2003 (Chen et al., 2012); the period prevalence of asthma was $11.9 \%$ between 2000 and 2007 (Hwang et al., 2010). Asthma and epilepsy are common causes of acute hospitalization. In the United States, epilepsy or convulsions make up $1 \%$ of all visits to the emergency department (ED) annually, and epilepsy uniformly constitutes $3.6 \%$ of all hospital admissions and admission rates across the country (Pallin et al., 2008; Stump, 2008). In the United States, acute asthma constitutes approximately $2 \%$ of all ED visits and $1.3 \%$ of all annual hospitalizations (Moorman et al., 2007). The annual global burden due to 23.4 million individuals with epilepsy in 2015 was estimated to be 12.4 million disability-adjusted life years (DALYs) (Feigin et al., 2017); 358.2 million individuals with asthma caused 26.2 million DALYs (Soriano et al., 2017). Thus, epilepsy and asthma are cost-intensive, complicated global health concerns (England et al., 2012; Pawankar, 2014; Nunes, Pereira \& Morais-Almeida, 2017) that tend to reduce patients' quality of life (Wang et al., 2012) and place a considerable burden on their family members. 
Asthma is associated with multiple neuropsychiatric disorders in children and adults, some

70

of which are anxiety, attention deficit hyperactivity disorder, autism, and depression (Fasmer et al., 2011; Van Lieshout \& Macqueen, 2012; Brumpton et al., 2013; Oh et al., 2015; Zheng et al., 2016, Choi et al., 2017). However, the association of epilepsy with asthma has never been clarified. Questions such as whether epilepsy can manifest as a bronchial spasm in asthma pathogenesis and whether people with asthma are more likely to develop epilepsy remain to be resolved. Immunity and inflammation seem to play a role in both disorders, with a sufficient body of experimental and clinical evidence suggesting that brain inflammation has the likelihood of predisposing a patient to and precipitating and perpetuating epileptogenesis. Certain systemic and neurological autoimmune disorders are reportedly affiliated with epilepsy, such as lupus cerebritis, Hashimoto's encephalopathy, multiple sclerosis, Rasmussen's encephalitis, linear scleroderma, and anti-N-methyl-D-aspartate receptor encephalitis (Chiang et al., 2009a; Chiang et al., 2009b; Vincent \& Crino, 2011; Devinsky, Schein \& Najjar, 2013). Proinflammatory cytokines play neuromodulatory functions, in addition to contributing to aberrant neuronal excitability underlying seizure disorders. Epilepsy and asthma share excitatory factors such as voltage-gated sodium channels, glutamate (i.e., N-methyl-D-aspartic acid), and acetylcholine, as well as inhibitory factors such as voltage-gated potassium channels, $\gamma$-aminobutyric acid (gamma-aminobutyric acid [GABA]), glycine, and taurine. One study proposed a pathogenetic mechanism of asthma, similar to that of epilepsy, as a syndrome pertaining to genetically predisposed or inducible membrane hyperexcitability (Hoang et al., 2006). These findings imply a complex association between the two disorders.

90 Researchers have attempted for numerous decades to link epilepsy to asthma. Studies published prior to 1970 (Levin, 1931; Forman, 1934; Speer, 1967; Fein \& Kamin, 1968) have 
92 hypothesized patients with asthma and other allergy conditions to be highly likely to experience 93 seizures (and vice versa). The mentioned studies have applied terms that include "neurologic 94 allergy" and "allergic epilepsy" to report allergies, concurrently presenting asthma, and epilepsy.

95 Furthermore, some studies executed after 1970 have established a link between asthma and epilepsy based on electroencephalographic findings (Mysik \& Czerniawska-Mysik, 1972; Cinca and Dimitriu, 1976; Abramson, 1978). However, despite growing bodies of evidence revealing such an association, only a few epidemiologic studies have been conducted on this association (Castaneda et al., 1998; Kobau et al., 2004; Strine et al., 2005; Bilan, 2008; Elliott, Moore \& Lu, 2008; Silverberg, Joks \& Durkin, 2014), all of which had small sample sizes or used a crosssectional design. Our review of the relevant literature showed that studies have yet to focus on this problem in Asian countries. In summary, large longitudinal studies in various populations are required to definitively explore the association between these two disorders and fill the knowledge gap.

In 1995, Taiwan implemented its National Health Insurance (NHI) program, which provides coverage for affordable, equitable, and universal health care to over $98 \%$ of Taiwan's 26 million residents (Chien et al., 2012). Similar to a natural laboratory setting, the NHI program's comprehensive health care coverage and continuous observation provide a special opportunity for the long-term observation of the correlation between epilepsy and asthma. Accordingly, in the present study, we utilized a longitudinal dataset from the National Health Insurance Research Database (NHIRD) and employed a large sample and representative data to execute a two-way population-based retrospective analysis in order to evaluate the asthma risk among patients with 113 epilepsy as well as the epilepsy risk among patients with asthma. 


\section{MATERIALS AND METHODS}

\section{Data source}

116 The data we used were subset data of the NHIRD, a database of longitudinal claims data

117 covering a cohort of 1 million people randomly selected from among all of the insured NHI

118 beneficiaries. Annually, the National Health Insurance Administration (NHIA) compiles NHI

119 data and then arranges the data as data files (e.g., registration data and original claims data), to

120 process reimbursements. For privacy protection, the files are deidentified through the scrambling

121 of patient and medical facility identification codes and are subsequently dispatched to the

122 National Health Research Institutes (NHRI), thus forming the original data files of the NHIRD.

123 We employed three types of data files - namely the ambulatory care claims, inpatient 124 claims, and registry of beneficiaries - that are linked using an encrypted yet distinctive personal 125 identification number. The files contain patient data regarding medical history and demographic 126 characteristics. Identifiers for individuals and medical facilities are unique to the NHIRD and 127 researchers, and they cannot be applied to trace patients or providers of health services. 128 Therefore, the requirement for full review was waived by the Institutional Review Board of 129 Kuang Tien General Hospital, and the use of these data was authorized by the NHRI.

\section{Study design and patients}

131 We evaluated the bidirectional epilepsy-asthma association by performing two analyses. In both 132 analyses, we used the same procedures for selecting the patients (Fig. 1). Specifically, for 133 analysis 1, we discovered patients with asthma [International Classification of Diseases, Ninth 134 Revision, Clinical Modification (ICD-9-CM) code 493] (i.e., the asthma group) and established a 
135 control group comprising individuals without asthma. For analysis 2, we discovered patients with

136 epilepsy (ICD-9-CM code 345) (i.e., the epilepsy group) and established a control group

137 comprising individuals without epilepsy. In analyses 1 and 2, we assigned to the patient groups

138 patients who had had inpatient claim or an initial ambulatory claim for asthma (analysis 1) or

139 epilepsy (analysis 2) during 1996-2013. For each patient, the diagnosis date was defined to be

140 the index date. The control groups were matched with the asthma (analysis 1) and epilepsy

141 (analysis 2) groups during the study period. We applied a 1:1 control-to-case ratio. To investigate

142 the temporal association of asthma with the subsequent occurrence of epilepsy, we excluded

143 from analysis 1 patients who had been diagnosed as having epilepsy before receiving a diagnosis

144 of asthma. Similarly, we excluded from analysis 2 patients who had been diagnosed as having

145 asthma before epilepsy. We followed up all patients to determine the epilepsy or asthma

146 incidence (analysis 1 and 2, respectively) until December 31, 2013, or their withdrawal from

147 NHI coverage.

\section{Statistical analysis}

149 The R Project for Statistical Computing (version 3.25) was used for all statistical analyses. In

150 both analyses, we compared the differences in the categorical and continuous variables in the

151 demographic data of the controls and patients by employing the chi-squared test and the

152 independent-sample t test, respectively. Sex, age, household income, and residence location were

153 analyzed. We stratified age into eight bands: $0-10,11-20,21-30,31-40,41-50,51-60,61-70$,

154 and $>70$ years. In addition, studies have reported that low socioeconomic status and low incomes

155 are key risk factors not only for epilepsy (Heaney et al., 2002; Kaiboriboon et al., 2013) but also

156 for the prevalence of asthma and increasing hospitalization due to asthma (Ray et al., 1998;

157 Markus et al., 2010). Thus, we employed household income as a confounding variable. We 
158 divided household income levels into four categories in terms of insurance premiums:

$159>40,000$ NT\$, 20,000-39,999NT\$, 1-19,999NT\$, and dependents. The NHIA and government

160 consider individuals who do not receive a salary, such as unemployed people, students, and

161 elderly people, as dependents. Similar to previous studies using NHIRD data, we classified

162 residence location into the following regions of Taiwan: northern, central, southern, and eastern

163 (Chie et al., 1995; Lu et al., 2006; Chen et al., 2012). Geographical variation, a demographic

164 factor, refers to differences among populations of a species in terms of genetic-based traits across

165 the natural geographic range of the species. Compared with other regions, northern Taiwan

166 comprises a higher number of economically and politically important cities, whereas eastern

167 Taiwan comprises less politico-economic importance and a different demographic structure, with

168 more indigenous people and a lower population density. One study reported geographic variation

169 in epidemiologic patterns of epilepsy within Taiwan; eastern Taiwan had significantly higher

170 prevalence and incidence of epilepsy than did other areas (Chen et al., 2012). Geographic

171 variation also reported epidemiologic patterns of asthma in other countries (Carvajal-Uruena et

172 al., 2005, Malhotra et al., 2014).

173 We assessed in analysis 1 the overall as well as sex-specific epilepsy incidence for patients

174 with asthma and their corresponding controls. By applying Cox proportional hazard regression

175 models, we estimated the hazard ratios (HRs) associated with epilepsy development in patients

176 with asthma relative to that in the control group. Geographical variation and household income

177 were adjusted for in the multivariate models. In addition, we applied Kaplan-Meier analysis to

178 derive plots of the proportion of seizure-free asthma. We used the same data analysis procedures

179 in both analyses. In analysis 2, we applied similar Cox regression models to evaluate the HRs

180 associated with asthma incidence in patients with epilepsy relative to that in the control group. 
181 For both sets of analyses, we set statistical significance at $\leq 0.05$. Additionally, we employed

182 Kaplan-Meier analysis to derive plots of the proportion of asthma-free seizures. 


\section{RESULTS}

184

185

186

187

188

189

190

191

192

193

194

195

196

197

198

199

200

201

202

203

\section{Asthma and risk of developing epilepsy}

In the 1996-2013 data, we discovered 150,827 patients with asthma and 150,827 age- and sexmatched controls (Table 1); among these patients, $31.42 \%$ were aged $0-10$ years and 51.05\% were female patients. Household income data were similar between the two groups. Patients with asthma were indicated to be more likely to reside or work in northern Taiwan, compared with the controls (52.01\% versus $45.24 \%$ ). We observed the median follow-up periods in the asthma and control groups to be 5.8 and 6.2 years, respectively.

The asthma group exhibited a higher epilepsy incidence (3.05 versus 2.26 per 1,000 personyears; see Table 2). As revealed by the regression model, patients with asthma were 1.39 times more likely to develop epilepsy [95\% confidence interval (CI) $1.33-1.45]$ after age, sex, income, and residence location had been controlled for. In both groups, the epilepsy incidence was higher in boys and men than it was in girls and women (Table 2). An association between asthma and increased epilepsy incidence was observed in both sexes, with a significantly higher relative risk estimate ( $\mathrm{t}$ test) in girls and women (adjusted HR: 1.52, 95\% CI: 1.42-1.64) than in boys and men (adjusted HR: 1.28, 95\% CI: 1.21-1.37). In addition, the epilepsy and control groups both had lower subsequent incidence of asthma in patients among the highest household income bracket (>NT\$40,000); among patients who lived in eastern Taiwan, both groups also had higher subsequent incidence of asthma.

The Kaplan-Meier analysis results revealed a consistent positive association between asthma and subsequent epilepsy development (Fig. 2). 
204 Epilepsy and corresponding risk of asthma

205 In the 1996-2013 data, we identified 25,274 patients with epilepsy and 25274 age-matched and

206

207

208

209

210

211

212

213

214

215

216

217

218

219

220

221

222

223

224

225

226

sex-matched controls (Table 3); among these patients, $20.3 \%$ were aged $<10$ years, $14.2 \%$ were aged $>70$ years, and $9.2 \%-12.8 \%$ were in each of the other age groups, and $45.5 \%$ were also female patients. We observed epilepsy group to be more likely to have a lower household income, compared with the control group (dependent-lowest income level: $18.9 \%$ versus $24.3 \%$ ). Moreover, patients with epilepsy were found to be more likely to reside or work in northern Taiwan than were their controls (45.3\% versus $42.8 \%)$. We noted the median follow-up periods in the epilepsy and control groups to be 6.1 and 6.4 years, respectively.

Although the epilepsy group exhibited a higher asthma incidence than did the control group (18.79 versus 17.75 per 1,000 person-years; Table 4), the regression model did not provide supportive evidence (adjusted HR: 0.96, 95\% CI: 0.91-0.999) after age, sex, income, and residence location had been controlled for. Although the results indicated a significant negative association, only mild influence was observed. A similar result was observed for male patients with epilepsy versus male individuals without epilepsy (adjusted HR: 0.91, 95\% CI: 0.86-0.97). However, we observed a positive association in some age subgroups, including people aged 0-10 and 31-40 years. In the 0-10-year subgroup, the epilepsy group exhibited a higher asthma incidence than did the control group (36.43 versus 33.85 per 1,000 person-years; adjusted HR: 1.09, 95\% CI: 1.01-1.16). In the 31-40-year subgroup, the epilepsy group exhibited a higher asthma incidence than did the control group (10.73 versus 7.81 per 1,000 person-years; adjusted HR: $1.34,95 \%$ CI: 1.12-1.61). By contrast, in the 11-20-year subgroup, the epilepsy group exhibited a lower asthma incidence than did the control group (7.92 versus 12.59 per 1,000 person-years; adjusted HR: $0.62,95 \% \mathrm{CI}: 0.51-0.75)$. In the $>70$-year subgroup, the epilepsy 
227 group exhibited a lower asthma incidence than did the control group (21.36 versus 24.46 per

228 1,000 person-years; adjusted HR: 0.78, 95\% CI: 0.69-0.87). In addition, the asthma and control

229 groups both had lower subsequent incidence of epilepsy among patients in the highest household

230 income bracket; among patients who lived in southern Taiwan, both groups also had lower

231 subsequent incidence of epilepsy.

232 The Kaplan-Meier analysis revealed epilepsy to be positively associated with subsequent 233 development of asthma within the first 7 years of epilepsy diagnosis. After 7 years, the results 234 indicated a negative association (Fig. 3). 


\section{DISCUSSION}

236 Our review of the relevant literature indicated the current study to be the first study to apply a

237 longitudinal dataset to execute a two-way population-based retrospective analysis in order to

238 evaluate the asthma risk among patients with epilepsy as well epilepsy risk among patients with

239 asthma. Our results confirm our hypothesis stating that patients with asthma are more likely to

240 develop epilepsy than are other individuals. In addition, female patients with asthma had a

241 significantly higher risk of epilepsy than did male patients with asthma. By contrast, patients

242 with epilepsy did not have a significantly increased risk of asthma compared with individuals

243 without epilepsy. However, the Kaplan-Meier analysis revealed epilepsy to be positively

244 associated with subsequent asthma development within the first 7 years of epilepsy diagnosis.

245 Furthermore, patients diagnosed as having epilepsy at the ages of 0-10 and 31-40 years were

246 indicated to be at an increased risk of asthma in later life, whereas those diagnosed at the ages of

$247 \quad 11-20$ and $>70$ years were indicated to be at a decreased risk of asthma in later life, compared

248 with other individuals. Similar to the results of previous studies, the present study revealed that

249 household income and geographic variation influenced incidence of asthma and epilepsy. Eastern

250 Taiwan had a higher incidence of epilepsy than did other areas, and southern Taiwan had a lower

251 incidence of asthma than did other areas. In addition, the population in the highest household

252 income bracket had lower incidences of epilepsy and asthma than did those in all lower brackets.

253 This study observed a significant temporal association of asthma with epilepsy risk. Some

254 clinical cases of epilepsy induced by long-standing asthma support our results (Costello \& Fox,

255 1936; Czubkowska et al., 1994). A study involving the surveillance of epilepsy in 800 children

256 with asthma reported that 26 children subsequently developed epilepsy and that asthmatic

257 children exhibited a significantly higher epilepsy prevalence rate than did the general population 
258 (Bilan \& Ghaffari, 2008). A U.S. population-based study (Silverberg, Joks \& Durkin, 2014) that

259 applied the 2007-2008 National Survey of Children's Health showed that children having $\geq 1$

260 allergy disease exhibited a higher frequency of epileptic episodes in their lifetime than did their

261 nonallergic counterparts.

Our results revealed that patients with asthma are more prone to epilepsy, but not vice versa.

263

264

265

266

267

268

269

270

271

272

273

274

275

276

277

278

279

280

The association between the two disorders may be primarily the result of the sequelae of asthma diagnosis. The most likely mechanism linking asthma to epilepsy development is anoxia due to frequent asthma attacks; however, we were unable to address this mechanism because the frequencies of asthma attacks and epileptic seizures could not be determine based on the current dataset. Another direct mechanism is hypocapnia. Hypocapnia, caused by hyperventilation, is commonly observed in patients with asthma (Bruton \& Holgate, 2005), and it can induce vasoconstriction causing cerebral hypoperfusion, diminishing oxygen delivery, and increasing neuronal excitation by releasing glutamate and dopamine. Hyperventilation engenders interictal discharges, which are particularly relevant in idiopathic seizures. Hyperventilation-induced activation is significantly more frequent in the temporal lobe than in other lobes (Guaranha et al., 2005). Furthermore, hyperventilation induces absence seizures (Wirrell et al., 1996). Apart from hypocapnia, the most common finding in terms of acid-base disturbances in patients with acute asthma is respiratory alkalosis (Mountain et al., 1990). The hypoxic effect of hypocapnia can exaggerate respiratory alkalosis, resulting in a left shift of the hemoglobin-oxygen dissociation curve. Furthermore, metabolic acidosis is prevalent in patients having severe asthma. The ultimate outcomes of the aforementioned processes include reduced cerebral blood flow and oxygen transport and delivery to the brain. Additionally, alkalosis was reported to promote calcium binding to plasma albumin, resulting in a reduced serum level of ionized calcium 
281 (Locatto et al., 1984), which can increase the probability of seizures. Adding xanthine-containing

282 antiasthmatic agents such as theophylline and aminophylline with potential central nervous

283 system (CNS) stimulant properties may further complicate the management of epilepsy because

284 of a lack of seizure control or precipitation of seizures in epileptic asthmatics. Theophylline-

285 associated seizures are considered a neurological emergency because they can be intractable.

286 Such seizures were reported in patients with low and therapeutic serum levels of theophylline,

287 indicating that seizures are not merely a result of dose-dependent drug toxicity (Dunn \& Parekh, 288 1991).

Our results revealed no significantly higher risk of asthma in patients with epilepsy than in individuals without epilepsy. Per our review of the relevant literature, no studies have determined whether epilepsy is a risk factor for asthma. However, we noted epilepsy to be positively associated with asthma development within the first 7 years of epilepsy diagnosis. In age subgroup analysis, patients diagnosed as having epilepsy aged $0-10$ or $31-40$ years were observed to have a high risk of asthma development in later life, whereas those diagnosed as having epilepsy aged 11-20 or $>70$ years were observed to have a low risk of asthma development in later life. Therefore, we believe that the epilepsy-asthma association is complicated and multifactorial. A Taiwanese study reported an asthma risk in children who experience febrile seizures; the findings of the study partially support our findings in the 0-10year subgroup (Lin et al., 2014). asthma association may be explained by several hypotheses. First, the two disorders perhaps share similar susceptible genes, including de novo mutations and cytokine genes. Moreover, cytokines oversecreted following a course of atopic reactions can pass through the blood-brain 
304 barrier, subsequently contributing to neuroinflammation and damaging neuron cells. Mao et al.

305 (2013) positively correlated interleukin (IL)-17a, IL-6, interferon (IFN)- $\gamma$, and IL-10 levels with

306 the severity and frequency of seizures and suggested that the IL-17a level was correlated

307 significantly with seizure frequency. Another study revealed the IL-6-174G $>$ C (rs1800795)

308 polymorphism to be significantly associated with the frequency of epileptic seizures and with the

309 incidence of drug-refractory epilepsy (Tiwari et al., 2012). Elevated levels of IL-6 and IL-1b

310 have been reported in patients with asthma, with the cytokines being particularly overexpressed

311 in the asthmatic bronchial epithelium (Ishioka, 1996; Thomas \& Chhabra, 2003; Martinez-Nunez

312 et al., 2014); this thus signifies that these cytokines might play in role in mediating

313 proinflammatory processes and airway hyperresponsiveness underlying asthmatic diseases. The

314 chronic neuroinflammation and neuronal damage resulting from the penetration of cytokines

315 through the blood-brain barrier raises patient susceptibility to epileptogenesis.

316 Second, specific viral infections and injury-associated proinflammatory cytokines can

317 trigger asthma and epilepsy; fever-related inflammatory cytokines as well as bacterial, specific

318 viral, and other pathogenic infections can also contribute to pathogenesis. Arteritis, ischemia, and

319 infarction are the main pathological outcomes of severe viral or bacterial CNS diseases and may

320 result in seizures (Sander, 2004). In addition, a mild infection may activate the IL-1 receptor-

321 toll-like receptor pathway; however, damage-associated molecular patterns including high

322 mobility group box 1 could engender such activation (van Vliet et al.). Specific viral infections,

323 such as adenovirus, herpes simplex virus, human herpesvirus-6, influenza, and respiratory

324 syncytial virus, were associated with febrile seizures (Lin et al., 2014). Rotavirus and norovirus

325 enteritis are associated with benign convulsions in childhood (Kim et al., 2016; Yorulmaz, Sert

326 \& Yilmaz, 2017). Furthermore, brain inflammation can be induced by the cyclooxygenase-2- 
327 induced production of prostaglandins (Fabene et al., 2008; Serrano et al., 2011). Additional

328 bodies of evidence indicate that mast cells and microglial cells as well as their interaction

329 substantially influence neuroinflammation (Chiou \& Hsieh, 2008; Skaper, Facci \& Giusti, 2014).

330 Channelopathies may partially contribute to comorbidities related to epilepsy and asthma.

331 Channelopathies refer to diseases engendered by ion channel defects that are caused by genetic

332 or acquired factors; ion-channel-encoding gene mutations are the most common cause of such

333 diseases. Such defects have been implicated in an extensive range of disorders and conditions,

334 which include migraine, epilepsy, deafness, blindness, diabetes, cardiac arrhythmia, hypertension,

335 asthma, cancer, and irritable bowel syndrome. Absence epilepsy is reportedly associated with

336 mutations in several ion-channel-encoding genes. For example, CACNA1H gene variants,

337 denoting the $\alpha 1 \mathrm{H}$ pore-forming subunit of T-type calcium channels, were observed in a patient

338 subset diagnosed as having childhood absence epilepsy (CAE) (Chen et al., 2003). Scholars have

339 additionally implicated missense GABRA1, GABRA6, GABARB3, and GABARG2

340 mutations - genes encoding numerous GABA-A receptor subunits — in CAE (Gurba et al., 2012;

341 Kim, 2014; Spillane, Kullmann \& Hanna, 2016). The onset of CAE is commonly in the age

342 range of 4 to 10 years, peaking at 5-7 years. More than half of all patients with CAE enter

343 remission in adolescence. Such characteristics of channelopathies could partially explain why in

344 our cohort of patients with epilepsy, those who had experienced the onset of epilepsy while aged

$3450-10$ years were indicated to be at a high risk of asthma development in later life, whereas those

346 who had experienced it while aged 11-20 years were indicated to be a decreased risk.

347 Some antiepileptic drugs (AEDs) might play roles in preventing and reducing the frequency

348 of asthma attacks. Studies have suggested that in addition to the suppression of inflammation and

349 bronchodilation, the control of excitatory mechanisms including voltage-gated sodium channel 
350 and glutamate receptors present in the brain and lung tissue, adjunctive glycine, and GABA

351 agonists could facilitate the development of highly effective and safe asthma prevention and

352 treatment strategies (Hoang et al., 2006; Hoang et al., 2010). Phenytoin was proven effective

353 against acute and paroxysmal asthma, with most phenytoin-treated patients exhibiting sustained

354 benefits even after treatment discontinuation (Shulman, 1942; Sayar \& Polvan, 1968; Jain \& Jain,

355 1991). Carbamazepine and sodium valproate have also been reported as having high

356 antiasthmatic activities (Lomia et al., 2005). Lidocaine, a local anesthetic used in status

357 epilepticus, works primarily by blocking sodium channels and decreasing membrane excitability.

358 It was also effective in treating patients with severe steroid-dependent asthma (Slaton, Thomas \&

359 Mbathi, 2013). Our previous research showed that the AED prescription rate among children

360 with epilepsy was lower than that among adolescents with epilepsy in Taiwan (Fig. 4) (Chiang \&

361 Cheng, 2014), and this could partially explain why in our epilepsy cohort of patients with

362 epilepsy, those who had experienced the onset of epilepsy while aged 0-10 years were indicated

363 to at a high risk of asthma development in later life, whereas those who had experienced it while

364 aged 11-20 years were indicated to be at a decreased risk.

365 The insular cortex might be critical in the epilepsy-asthma association. Dyspnea is a high-

366 impact symptom of asthma. A study noted that the periaqueductal gray matter downregulated

367 affect-related insular cortex activity during sensations of pain and dyspnea in patients with

368 asthma. The implicated insular cortex and periaqueductal gray matter might present as a

369 mechanism of neuronal habituation, thereby ameliorating the corresponding unpleasantness of

370 affective dyspnea in such patients (von Leupoldt et al., 2009). In another study, a group of

371 patients with insular cortex lesions were indicated to experience reduced perceptual sensitivity to

372 dyspnea unpleasantness, compared with the corresponding control group (Schon et al., 2008). By 
373 contrast, some case reports have demonstrated that in patients with insular cortex epilepsy, a

374 seizure attack could clinically present as dyspnea and chest tightness during sleep, and this could

375 be difficult to distinguish from asthma-associated dyspnea.

376 Our study involves certain limitations that warrant consideration. First, in the claims data,

377 the medical coding accuracy may influence data validity; this is because only people who sought

378 medical aid were enlisted. In addition, diagnoses were based on inpatient claims and ambulatory

379 care claims; hence, some may have represented a tentative diagnosis, rather than a final diagnosis.

380 However, epilepsy is stigmatized in Taiwan, and thus identifying epilepsy in patients may be

381 difficult in some cases. Although physicians apply the same diagnostic criteria, biases may be

382 possible. However, the NHIA has a medical review system to monitor insurance claims;

383 consequently, the effect of diagnostic validity on our findings is minimal. Second, the NHIRD

384 limitations necessitated the use of only ICD-9-CM codes (i.e., 345 for epilepsy and 493 for

385 asthma) for case patient identification. Further information such as syndromes, epilepsy

386 classification, and asthma severity level was unavailable. Third, the NHIRD does not include

387 medical record information on factors that might have exerted a minor influence on our results,

388 such as the comorbidities of atopic dermatitis and allergic dermatitis, food allergies, family

389 histories, personal lifestyles, and environmental factors. Fourth, the control group may have

390 included patients with undiagnosed asthma or epilepsy. This sampling bias may be slightly

391 overestimated in the control group but not sufficiently to affect the interpretation of the results.

392 Finally, we did not analyze drug-related pathogenic or therapeutic effects such as the 393 antiasthmatic effect of AEDs and epileptogenicity of xanthine-containing antiasthmatic agents. 


\section{CONCLUSION}

395 Despite the limitations in this study, our data suggest a complex epilepsy-asthma association.

396 Patients with asthma had a higher risk of epilepsy than did individuals without asthma. By

397 contrast, risk of asthma did not differ significantly between patients with epilepsy and

398 individuals without epilepsy. However, patients experiencing epilepsy onset at specific ages had

399 a higher or lower risk of asthma development than did individuals without epilepsy. The results

400 revealed that patients with asthma are more prone to epilepsy, but not vice versa. One of the

401 most likely explanations of the association between asthma and epilepsy is anoxia due to

402 frequent asthma attacks or due to the side effects of antiasthma medication. To effectively fill the

403 knowledge gap, future studies are recommended to focus on incidence of epilepsy in patients

404 with asthma of varying severity or in patients with varying levels of asthma control and

405 compliance. Another possible explanation for the association between these two disorders is that

406 they share common pathogenic mechanisms, which include hypocapnia, chronic inflammation,

407 immune dysregulation, genetic susceptibility, channelopathies, drug-related pathogenic or

408 therapeutic effects, and environmental factors. Additional studies should be conducted on these

409 hypotheses to elucidate the mechanisms that link asthma, atopic dermatitis, or a broader atopy

410 spectrum to epilepsy. In addition, our findings contributed to the literature on socioeconomic

411 disparity, including the influence of household income and geographic variation on patients with

412 epilepsy and those with asthma; physicians and public health policymakers should focus on this

413 aspect. Reducing such disparity requires interventions to prevent epilepsy and asthma and

414 improve the quality of care for these disorders. 


\section{Acknowledgments}

416 The authors thank the NHRI and the NHIA for providing the study data. This manuscript

417 was edited by Wallace Academic Editing. 


\section{REFERENCES}

419 Abramson HA. 1978. Asthma, epilepsy and allergy. Journal of Asthma Research 15:159-162.

420

421

422

423

424

425

426

427

428

429

430

431

432

433

434

435

436

437

Bilan N, Ghaffari S. 2008. Association of asthma and epilepsy. Research Journal of Biological Sciences 3:1370-1372.

Browne TR, Holmes GL. 2001. Epilepsy. New England Journal of Medicine 344:1145-1151. DOI: 10.1056/NEJM200104123441507.

Brumpton BM, Leivseth L, Romundstad PR, Langhammer A, Chen Y, Camargo CA JR, Mai XM. 2013. The joint association of anxiety, depression and obesity with incident asthma in adults: the hunt study. International Journal of Epidemiology 42:1455-1463.

Bruton A, Holgate ST. 2005. Hypocapnia and asthma: a mechanism for breathing retraining? Chest 127:1808-1811. DOI: 10.1093/ije/dyt151.

Carvajal -Uruena I, Garcia-Marcos L., Busquets-Monge R, Morales Suarez-Varela M, Garcia de Andoin N, Batlles-Garrido J., Blanco-Quiros A, Lopez-Silvarrey A, Garcia-Herandez G, Guillen-Grimaj F, Gonzalez-Diaz C, Bellido-Blasco J. 2005. Geographic variation in the prevalence of asthma symptoms in Spanish children and adolescents. International Study of Asthma and Allergies in Childhood (ISAAC) Phase 3, Spain. Archivos de bronconeumologia 41:659-666.

Castaneda GY, Heilbroner PL, Shah N, Forem S, Fish I. 1998. Asthma and epilepsy: are they related? a retrospective study. Journal of Child Neurology 13:283-285. DOI: $10.1177 / 088307389801300608$. 
438 Chang BS, Lowenstein DH. 2003. Epilepsy. New England Journal of Medicine 349:1257-1266.

439 DOI: 10.1056/NEJMra022308.

440 Chen CC, Chen LS, Yen MF, Chen HH, Liou HH. 2012. Geographic variation in the age- and 441 gender-specific prevalence and incidence of epilepsy: analysis of taiwanese national health

Chen Y, Lu J, Pan H, Zhang Y, Wu H, Xu K, Liu X, Jiang Y, Bao X, Yao Z, Ding K, Lo W H, Qiang B, Chan P, Shen Y, Wu X. 2003. Association between genetic variation of cacna1h and childhood absence epilepsy. Annals of Neurology 54:239-243.

Chiang KL, Chang KP, Wong TT, Hsu TR. 2009a. Linear scleroderma "en coup de sabre": initial presentation as intractable partial seizures in a child. Pediatrics \& Neonatology 50:294-298.

Chiang KL, Cheng CY. 2014. Prevalence and neuro-psychiatric comorbidities of pediatric epilepsy in taiwan: a national population-based study. Epilepsy Research 108:1451-1460.

450

451

452

453

454

455

456

457

Chiang KL, Wong TT, Kwan SY, Hsu TR, Wang CH, Chang KP. 2009b. Finding on brain MRI mimicking focal cortical dysplasia in early rasmussen's encephalitis: a case report and review. Child's Nervous System 25:1501-1506.

Chie WC, Chen CF, Chen CJ, Chang CL, Liaw YP, Lin RS. 1995. Geographic variation of breast cancer in taiwan: international and migrant comparison. Anticancer Research $15: 2745-2749$.

Chien IC, Lin CH, Chou YJ, Chou P. 2012. Prevalence, incidence, and stimulant use of attention-deficit hyperactivity disorder in taiwan, 1996-2005: a national population-based 
study. Social Psychiatry and Psychiatric Epidemiology 47:1885-1890.

459 Chiou HH, Hsieh LP. 2008. Parenting stress in parents of children with epilepsy and asthma. 460 Journal of Child Neurology 23:301-306.

461 Choi S, Kim SH, Lee JS. 2017. Association between depression and asthma in korean adults. 462 Allergy \& Asthma Proceedings 38:238-239.

463 Cinca I, Dimitriu R. 1976. Clinical and electroencephalographic study of allergic epilepsy. 464 Revista de Medicina Interna, Neurolgie, Psihiatrie, Neurochirurgie, Dermato-Venerologie. 465 Neurologie, Psihiatrie, Neurochirurgie 21:215-224.

466 Costello K, Fox JT. 1936. A case showing an unusual relationship between asthma and epilepsy. $467 \quad$ Lancet 1:660.

Czubkowska I, Karkowska B, Najberg E, Zychowicz C, Nowacka K. 1994. Epilepsy as a 469 complication of bronchial asthma. Polski Tygodnik Lekarski 49:448-450.

Devinsky O, Schein A, Najjar S. 2013. Epilepsy associated with systemic autoimmune disorders. Epilepsy Currents 13:62-68.

Dunn DW, Parekh HU. 1991. Theophylline and status epilepticus in children. Neuropediatrics $22: 24-26$

Elliott JO, Moore JL, Lu B. 2008. Health status and behavioral risk factors among persons with 475 epilepsy in ohio based on the 2006 behavioral risk factor surveillance system. Epilepsy \& Behavior 12:434-444.

477 England MJ, Liverman CT, Schultz AM, Strawbridge LM. 2012. Epilepsy across the spectrum: 
478

479

480

481

482

483

484

485

486

487

488

489

490

491

492

493

494

495

496

497

promoting health and understanding. A summary of the institute of medicine report. Epilepsy \& Behavior 25:266-276.

Fabene PF, Navarro Mora G, Martinello M, Rossi B, Merigo F, Ottoboni L, Bach S, Angiari S, Benati D, Chakir A, Zanetti L, Schio F, Osculati A, Marzola P, Nicolato E, Homeister JW, Xia L, Lowe JB, Mcever RP, Osculati F, Sbarbati A, Butcher EC, Constantin G. 2008. A role for leukocyte-endothelial adhesion mechanisms in epilepsy. Nature Medicine 14:13771383.

Fasmer OB, Halmoy A, Eagan TM, Oedegaard KJ, Haavik J. 2011. Adult attention deficit hyperactivity disorder is associated with asthma. BMC Psychiatry 11:128.

Feigin VL, Abajobir AA, Abate KH, Abd-Allah F, Abdulle AM, Abera SF, Abyu GY, Ahmed MB, Aichour AN, Aichour I. 2017. Global, regional, and national burden of neurological disorders during 1990-2015: a systematic analysis for the Global Burden of Disease Study 2015. The Lancet Neurology 16:877-897. DOI: 10.1016/S1474-4422(17)30299-5.

Fein BT, Kamin PB. 1968. Allergy, convulsive disorders and epilepsy. Annals of Allergy, Asthma \& Immunology 26:241-247.

Forman J. 1934. Atopy as a cause of epilepsy. Archives of Neurology and Psychiatry 32(3):517522.

Guaranha MS, Garzon E, Buchpiguel CA, Tazima S, Yacubian EM, sakamoto AC. 2005. Hyperventilation revisited: physiological effects and efficacy on focal seizure activation in the era of video-eeg monitoring. Epilepsia 46:69-75. 
498 Gurba KN, Hernandez CC, Hu N, Macdonald RL. 2012. Gabrb3 mutation, g32r, associated with 499 childhood absence epilepsy alters alphalbeta3gamma2l gamma-aminobutyric acid type a 500 (gabaa) receptor expression and channel gating. Journal of Biological Chemistry $501 \quad 287: 12083-12097$.

502 Heaney DC, Macdonald BK, Everitt A, Stevenson S, Leonardi GS, Wilkinson P, Sander JW. 503 2002. Socioeconomic variation in incidence of epilepsy: prospective community based 504

505

506

507

508

509

510

511

512

513

514

515

516

517

518

Hoang BX, Levine SA, Shaw DG, Pham P, Hoang C. 2006. Bronchial epilepsy or bronchopulmonary hyper-excitability as a model of asthma pathogenesis. Medical Hypotheses 67:1042-1051.

Hoang BX, Shaw DG, Pham P, Levine SA. 2010. Treating asthma as a neuroelectrical disorder. Inflammation \& Allergy-Drug Targets 9:130-134.

Hwang CY, Chen YJ, Lin MW, Chen TJ, Chu SY, Chen CC, Lee DD, Chang YT, Wang WJ, Liu HN. 2010. Prevalence of atopic dermatitis, allergic rhinitis and asthma in Taiwan: a national study 2000 to 2007. Acta dermato-venereologica 90:589-594. DOI: 10.2340/000155550963.

Ishioka S. 1996. Role of cytokines in pathophysiology of asthma. Nihon Naika Gakkai Zasshi $85: 184-188$.

Jain S, Jain KC. 1991. Effect of phenytoin sodium in the management of poorly controlled bronchial asthma at a rural health center in phalodi, rajasthan, India. Journal of Asthma 28:201-211. 
519 Kaiboriboon K, Bakaki PM, Lhatoo SD, Koroukian S. 2013. Incidence and prevalence of treated 520 epilepsy among poor health and low-income Americans. Neurology 80:1942-1949. DOI:

521 10.1212/WNL.0b013e318293e1b4.

522 Kim GH, Byeon JH, Lee DY, Jeong HJ, Eun BL. 2016. Norovirus in benign convulsions with 523 mild gastroenteritis. Italian Journal of Pediatrics 42:94.

524 Kim JB. 2014. Channelopathies. Korean Journal of Pediatrics 57:1-18.

525 Kobau R, Diiorio CA, Price PH, Thurman DJ, Martin LM, Ridings DL, Henry TR. 2004. 526 Prevalence of epilepsy and health status of adults with epilepsy in georgia and tennessee: 527 behavioral risk factor surveillance system, 2002. Epilepsy \& Behavior 5:358-366.

528 Levin SJ. 1931. Allergic epilepsy. Journal of the American Medical Association 97:1624.

529 Lin WY, Muo CH, Ku YC, Sung FC, Kao CH. 2014. Risk of subsequent asthma in children with 530 febrile seizures: a nationwide population-based retrospective cohort study. Pediatric $531 \quad$ Neurology 51:795-799.

532 Locatto ME, Fernandez MC, Caferra DA, Gimenez MC, Vidal MC, Puche RC. 1984. 533 Respiratory alkalosis and reduced plasmatic concentration of ionized calcium in rats treated 534 with 1,25 dihydroxycholecalciferol. Calcified Tissue International 36:604-607.

535 Lomia M, Chapichadze Z, Pruidze M, Platonov P. 2005. Efficacy of monotherapy with 536 carbamazepine and valproic acid in patients with bronchial asthma: is asthma neurological 537 disease. Internet Journal of Neurology 4:1-4.

538 Lu SN, Su WW, Yang SS, Chang TT, Cheng KS, Wu JC, Lin HH, Wu SS, Lee C M, 

geographic variations of hepatitis b virus and hepatitis c virus-associated hepatocellular carcinoma in taiwan. International Journal of Cancer 119:1946-1952.

Malhotra K, Baltrus P, Zhang S, Mcroy L, Immergluck LC, Rust G. 2014. Geographic and racial variation in asthma prevalence and emergency department use among Medicaid-enrolled

Mao LY, Ding J, Peng WF, Ma Y, Zhang YH, Fan W, Wang X. 2013. Interictal interleukin-17a levels are elevated and correlate with seizure severity of epilepsy patients. Epilepsia

Markus AR., Lyon M. \& Rosenbaum SJ. 2010. Changing policy: The elements for improving childhood asthma outcomes. Washington, DC: Department of Health Policy, the George Washington University School of Public Health and Health Services.

Martinez-Nunez RT, Bondanese VP, Louafi F, Francisco-Garcia AS, Rupani H, Bedke N, 553 Holgate S, Howarth PH, Davies DE, Sanchez-Elsner T. 2014. A microrna network

Masoli M, Fabian D, Holt S, Beasley R. 2004. The global burden of asthma: executive summary of the gina dissemination committee report. Allergy 59:469-478. 
Mountain RD, Heffner JE, Brackett NC JR, Sahn SA. 1990. Acid-base disturbances in acute asthma. Chest 98:651-655.

563

564

565

566

567

568

569

570

571

572

573

574

575

576

577

578

579

Mysik M, Czerniawska-Mysik G. 1972. Allergic reactions and epilepsy attacks. Przeglad Lekarski 29:325-330.

Nunes C, Pereira AM, Morais-Almeida M. 2017. Asthma costs and social impact. Asthma Research and Practice 3:1. DOI: 10.1186/s40733-016-0029-3.

Oh S, Ji H, Barzman D, Lin PI, Hutton J. 2015. Pediatric asthma and autism-genomic perspectives. Clinical and Translational Medicine 4:37. DOI: 10.1186/s40169-015-0078-x.

Olin JT, Wechsler ME. 2014. Asthma: pathogenesis and novel drugs for treatment. BMJ 349:g5517. DOI: 10.1136/bmj.g5517.

Pallin DJ, Goldstein JN, Moussally JS, Pelletier AJ, Green AR, Camargo CA JR. 2008. Seizure visits in us emergency departments: epidemiology and potential disparities in care. International Journal of Emergency Medicine 1:97-105.

Pawankar R. 2014. Allergic diseases and asthma: a global public health concern and a call to action. World Allergy Organization Journal 7:12. DOI: 10.1186/1939-4551-7-12.

Ray, NF, Thamer, M, Fadillioglu B, Gergen PJ. 1998. Race, income, urbanicity, and asthma hospitalization in California: a small area analysis. Chest 113:1277-1284. DOI: 10.1378/chest.113.5.1277.

Sander JW. 2004. Infectious agents and epilepsy. National Academies Press (US). 
580 Sayar B, Polvan O. 1968. Epilepsy and bronchial asthma. Lancet 1:1038.

581 Schon D, Rosenkranz M, Regelsberger J, Dahme B, Buchel C, Von Leupoldt A. 2008. Reduced

582 perception of dyspnea and pain after right insular cortex lesions. American Journal of 583 Respiratory and Critical Care Medicine 178:1173-1179.

584 Serrano GE, Lelutiu N, Rojas A, Cochi S, Shaw R, Makinson CD, Wang D, Fitzgerald G A, 585 Dingledine R. 2011. Ablation of cyclooxygenase-2 in forebrain neurons is neuroprotective 586 and dampens brain inflammation after status epilepticus. Journal of Neuroscience 31:14850$587 \quad 14860$.

588 589

Shulman MH. 1942. The use of dilantin sodium in bronchial asthma: a preliminary report. New England Journal of Medicine 226:260-264.

Silverberg JI, Joks R, Durkin HG. 2014. Allergic disease is associated with epilepsy in childhood: a us population-based study. Allergy 69:95-103.

Skaper SD, Facci L, Giusti P. 2014. Mast cells, glia and neuroinflammation: partners in crime? Immunology 141:314-327.

Slaton RM, Thomas RH, Mbathi JW. 2013. Evidence for therapeutic uses of nebulized lidocaine in the treatment of intractable cough and asthma. Annals of Pharmacotherapy 47:578-585.

Soriano JB, Abajobir AA, Abate KH, Abera SF, Agrawal A, Ahmed MB, Aichour AN, Aichour I, Aichour MTE, ALAM K. 2017. Global, regional, and national deaths, prevalence, disability-adjusted life years, and years lived with disability for chronic obstructive pulmonary disease and asthma, 1990-2015: a systematic analysis for the Global Burden of 

2600(17)30293-X.

602 603

604

605

606

607

608

609

610

611

612

613

614

615

616

617

618

619

Speer F. 1967. Neurologic allergy: the problem of classification. Annals of Allergy, Asthma \& Immunology 25:421-425.

Spillane J, Kullmann DM, Hanna MG. 2016. Genetic neurological channelopathies: molecular genetics and clinical phenotypes. The Journal of Neurology, Neurosurgery, \& Psychiatry 87:37-48.

Strine TW, Kobau R, Chapman DP, Thurman DJ, Price P, Balluz LS. 2005. Psychological distress, comorbidities, and health behaviors among u.s. Adults with seizures: results from the 2002 national health interview survey. Epilepsia 46:1133-1139.

Stump E. 2008. Hospital admissions for epilepsy and convulsions increase nationwide. Neurology today 8. DOI: 10.1097/01.nt.0000314455.74483.e0, 113.

Thomas SS, Chhabra SK. 2003. A study on the serum levels of interleukin-1beta in bronchial asthma. Journal of Indian Medical Association 101, 282, 284, 286 passim.

Tiwari P, Dwivedi R, Mansoori N, Alam R, Chauhan UK, Tripathi M, Mukhopadhyay AK. 2012. Do gene polymorphism in il-1beta, tnf-alpha and il-6 influence therapeutic response in patients with drug refractory epilepsy? Epilepsy Research 101:261-267.

Van Lieshout RJ, Macqueen GM. 2012. Relations between asthma and psychological distress: an old idea revisited. Chemical Immunology and Allergy 98:1-13.

Van Vliet EA, Aronica E, Vezzani A, Ravizza T. 2017. Neuroinflammatory pathways as 
treatment targets and biomarker candidates in epilepsy: emerging evidence from preclinical

621 and clinical studies. Neuropathology and Applied Neurobiology DOI:10.1111/nan.12444.

622 Vincent A, Crino PB. 2011. Systemic and neurologic autoimmune disorders associated with 623 seizures or epilepsy. Epilepsia 52(3):12-17.

624 Von Leupoldt A, Sommer T, Kegat S, Eippert F, Baumann HJ, Klose H, Dahme B, Buchel C. 625 2009. Down-regulation of insular cortex responses to dyspnea and pain in asthma. American 626 Journal of Respiratory and Critical Care Medicine 180:232-238.

627 Wang J, Wang Y, Wang LB, Xu H Zhang XL. 2012. A comparison of quality of life in 628 adolescents with epilepsy or asthma using the short-form health survey (sf-36). Epilepsy $629 \quad$ Research 101:157-165.

630 Wirrell EC, Camfield PR, Gordon KE, Camfield CS, Dooley JM, Hanna BD. 1996. Will a 631 critical level of hyperventilation-induced hypocapnia always induce an absence seizure? $632 \quad$ Epilepsia 37:459-462.

Yorulmaz A, Sert S, Yilmaz FH. 2017. Evaluation of benign afebrile convulsions in 16 children 634 with rotavirus gastroenteritis. Acta Neurologica Belgica 117:441-445. spectrum disorder: a meta-analysis. Plos One 11:e0156662. 


\section{FIGURE CAPTIONS}

638 Figure 1 Flowchart of study patient selection.

639 Figure 2 Survival curve of epilepsy development among patients with asthma and the control 640 group.

641 Figure 3 Survival curve of asthma development among patients with epilepsy and the control 642 group.

643 Figure 4 Prevalence of epilepsy and epilepsy with AED prescription. (Data reference: Chiang \& 644 Cheng, 2014) 


\section{Table 1 (on next page)}

Demographic characteristics of patients with asthma and controls. 
1 Table 1 Demographic characteristics of patients with asthma and controls.

\begin{tabular}{ccccc}
\hline Nonasthma comparison group & Patients with asthma & p-value \\
$\mathbf{n}=150827$ & percentile & $\mathbf{n}=150827$ & percentile &
\end{tabular}

\section{Characteristic}

Age (years)

0-10

11-20

21-30

$31-40$

41-50

51-60

61-70

$>70$

Mean (SD) of Age
47394

11885

13044

16530

17076

16214

14640

14034

33.41 (25.51)
$31.42 \%$

$7.88 \%$

$8.65 \%$

$10.96 \%$

$11.32 \%$

$10.75 \%$

$9.71 \%$

$9.30 \%$
47394

11885

13044

16530

17076

16214

14640

14034

$31.42 \%$

$7.88 \%$

$8.65 \%$

$10.96 \%$

$11.32 \%$

$10.75 \%$

$9.71 \%$

$9.30 \%$

Sex

Female

Male

Income

0

$<20000$

20000-39999

$>40000$
76998

73819

69082

28711

38688

14336

Residence location

North

68234

37455

40592

3505

1031

Off island
$51.05 \%$

$48.94 \%$

$45.80 \%$

$19.04 \%$

$25.65 \%$

$9.50 \%$

$45.24 \%$

$24.83 \%$

$26.91 \%$

$2.32 \%$

$0.68 \%$
76998

73819

70137

27032

39128

14520

78449

35953

31785

3715

915
$33.41(25.51) \quad 1.00 *$

.

$2 \quad *$ p-value was calculated by Chi-square statistic.

$3 * *$ p-value was calculated by t statistic. 
Table 2 (on next page)

HRs for incidence of epilepsy in relation to asthma. 
Table 2 HRs for incidence of epilepsy in relation to asthma.

$\frac{\text { Table } 2 \text { HRs for incidence of epilepsy in relation to asthma. }}{\text { No asthma comparison Group }}$

Hazard ratio and $95 \% \mathrm{CI}$

(patient with asthma vs. comparison

\begin{tabular}{|c|c|c|c|c|c|c|c|c|}
\hline \multirow{3}{*}{ ALL } & \multirow[b]{2}{*}{$\begin{array}{l}\text { Case } \\
\mathrm{s}\end{array}$} & \multirow[b]{2}{*}{ PY } & \multirow{2}{*}{ Incidence $^{\mathrm{a}}$} & \multirow{2}{*}{ Cases } & \multirow{2}{*}{ PY } & \multirow{2}{*}{ Incidence $^{\mathrm{a}}$} & \multicolumn{2}{|l|}{ group) } \\
\hline & & & & & & & Unadjusted & Adjusted $^{\mathrm{b}}$ \\
\hline & 3264 & 1446014 & 2.26 & 4236 & 1386893 & 3.05 & $1.35^{*}(1.29-1.41)$ & $\begin{array}{l}1.39 *(1.33- \\
1.45)\end{array}$ \\
\hline \multicolumn{9}{|c|}{ Stratified by SEX } \\
\hline Female & 1482 & 726276 & 2.04 & 2079 & 694427 & 2.99 & $1.47 *(1.37-1.57)$ & $\begin{array}{l}1.52 *(1.42- \\
1.64)\end{array}$ \\
\hline Male & 1782 & 719738 & 2.48 & 2157 & 692466 & 3.12 & $1.25 *(1.18-1.33)$ & $\begin{array}{l}1.28 *(1.21- \\
1.37)\end{array}$ \\
\hline \multicolumn{9}{|c|}{ Stratified by AGE } \\
\hline $0-10$ & 878 & 471260 & 1.86 & 1141 & 488971 & 2.33 & $1.27 *(1.16-1.38)$ & --- \\
\hline $11-20$ & 184 & 125089 & 1.47 & 178 & 113217 & 1.57 & $1.05(0.85-1.29)$ & --- \\
\hline $21-30$ & 140 & 112963 & 1.24 & 173 & 111653 & 1.55 & $1.26 *(1.01-1.57)$ & --- \\
\hline $31-40$ & 191 & 143218 & 1.33 & 296 & 140908 & 2.10 & $1.57 *(1.31-1.89)$ & --- \\
\hline $41-50$ & 249 & 153727 & 1.62 & 418 & 151436 & 2.76 & $1.71 *(1.46-1.99)$ & --- \\
\hline $51-60$ & 359 & 148633 & 2.42 & 495 & 134844 & 3.67 & $1.52 *(1.33-1.74)$ & --- \\
\hline $61-70$ & 541 & 142983 & 3.78 & 732 & 130915 & 5.59 & $1.48 *(1.33-1.66)$ & --- \\
\hline$>70$ & 722 & 148142 & 4.88 & 803 & 114948 & 6.99 & $1.39 *(1.26-1.54)$ & --- \\
\hline \multicolumn{9}{|c|}{ Stratified by INCOME } \\
\hline 0 & 1614 & 677069 & 2.38 & 1981 & 660961 & 3.00 & $1.25^{*}(1.17-1.33)$ & --- \\
\hline$<20000$ & 784 & 278760 & 2.81 & 1011 & 253786 & 3.98 & $1.41 *(1.28-1.55)$ & --- \\
\hline 20000-39999 & 744 & 362018 & 2.06 & 1073 & 347930 & 3.08 & $1.50 *(1.37-1.65)$ & --- \\
\hline$>40000$ & 122 & 128167 & 0.95 & 171 & 124216 & 1.38 & $1.46 *(1.15-1.84)$ & --- \\
\hline \multicolumn{9}{|c|}{ Stratified by LOCATION } \\
\hline $\mathrm{N}$ & 1385 & 650132 & 2.13 & 1885 & 713899 & 2.64 & $1.23 *(1.15-1.32)$ & --- \\
\hline $\mathrm{C}$ & 958 & 360406 & 2.66 & 1230 & 335659 & 3.66 & $1.38 *(1.27-1.50)$ & --- \\
\hline $\mathrm{S}$ & 802 & 391822 & 2.05 & 953 & 295787 & 3.22 & $1.57 *(1.43-1.73)$ & --- \\
\hline $\mathrm{E}$ & 97 & 33574 & 2.89 & 139 & 33990 & 4.09 & $1.41 *(1.08-1.82)$ & --- \\
\hline $\mathrm{O}$ & 22 & 10081 & 2.18 & 29 & 7558 & 3.84 & $1.71(0.98-2.97)$ & --- \\
\hline
\end{tabular}

2 PY: person-years at risk

3 a The incidence is per 1000 person-year

4 b Adjusted for age, sex, income and residence location

$5 *$ Significance at 0.05 level 


\section{Table 3 (on next page)}

Demographic characteristics of patients with epilepsy and controls. 
1 Table 3 Demographic characteristics of patients with epilepsy and controls.

\begin{tabular}{|c|c|c|c|c|c|}
\hline & \multicolumn{2}{|c|}{ Nonepilepsy comparison group } & \multicolumn{2}{|c|}{ Patients with epilepsy } & \multirow[t]{2}{*}{ p-val } \\
\hline & $\mathrm{n}=\mathbf{2 5 2 7 4}$ & percentile & $\mathrm{n}=\mathbf{2 5 2 7 4}$ & percentile & \\
\hline \multicolumn{6}{|c|}{ Characteristic } \\
\hline \multicolumn{6}{|c|}{ Age (years) } \\
\hline $0-10$ & 5122 & $20.27 \%$ & 5122 & $20.27 \%$ & \\
\hline $11-20$ & 2326 & $9.20 \%$ & 2326 & $9.20 \%$ & \\
\hline $21-30$ & 2515 & $9.95 \%$ & 2515 & $9.95 \%$ & \\
\hline $31-40$ & 2798 & $11.07 \%$ & 2798 & $11.07 \%$ & \\
\hline $41-50$ & 3231 & $12.78 \%$ & 3231 & $12.78 \%$ & \\
\hline $51-60$ & 3010 & $11.91 \%$ & 3010 & $11.91 \%$ & \\
\hline $61-70$ & 2688 & $10.64 \%$ & 2688 & $10.64 \%$ & \\
\hline$>70$ & 3584 & $14.18 \%$ & 3584 & $14.18 \%$ & \\
\hline \multicolumn{2}{|c|}{ Mean (SD) of Age } & $39.13(25.92)$ & & $39.13(25.92)$ & $1.00 *$ \\
\hline
\end{tabular}

Sex

$\begin{array}{llllll}\text { Female } & 11499 & 45.50 \% & 11499 & 45.50 \% & \\ \text { Male } & 13775 & 54.50 \% & 13775 & 54.50 \% & 1.00 * *\end{array}$

Income

$\begin{array}{llllll}0 & 9715 & 38.44 \% & 10313 & 40.80 \% & \\ <20000 & 5215 & 20.63 \% & 6707 & 26.54 \% & \\ 20000-39999 & 7469 & 29.55 \% & 6597 & 26.10 \% & \\ >40000 & 2875 & 11.38 \% & 1657 & 6.56 \% & <2.2 \mathrm{e}-16^{*}\end{array}$

Residence location

$\begin{array}{llllll}\text { North } & 10815 & 42.79 \% & 11447 & 45.29 \% & \\ \text { Central } & 7148 & 28.28 \% & 6329 & 25.04 \% & \\ \text { South } & 6306 & 24.95 \% & 6665 & 26.37 \% & \\ \text { East } & 818 & 3.24 \% & 644 & 2.55 \% & \\ \text { Off island } & 187 & 0.74 \% & 189 & 0.75 \% & <2.2 \mathrm{e}-16^{*}\end{array}$

$2 *^{*}$-value was calculated by Chi-square statistic.

$3 * * \mathrm{p}$-value was calculated by t statistic. 


\section{Table 4 (on next page)}

HRs for incidence of asthma in relation to epilepsy. 
1 Table 4 HRs for incidence of asthma in relation to epilepsy.

Hazard ratios for incidence of asthma in relation to epilepsy

\begin{tabular}{|c|c|c|c|c|c|c|c|c|}
\hline & \multicolumn{3}{|c|}{ No epilepsy comparison Group } & \multicolumn{3}{|c|}{ Patient with epilepsy } & \multicolumn{2}{|c|}{$\begin{array}{l}\text { Hazard ratio and } 95 \% \text { CI } \\
\text { (patient with Epilepsy vs. comparison group) }\end{array}$} \\
\hline & Cases & PY & Incidence $^{\mathrm{a}}$ & Cases & PY & Incidence $^{\mathrm{a}}$ & Unadjusted & Adjusted $^{\mathrm{b}}$ \\
\hline ALL & 4235 & 238577 & 17.75 & 3752 & 199639 & 18.79 & $1.00(0.96-1.04)$ & $0.96^{*}(0.91-0.999)$ \\
\hline \multicolumn{9}{|c|}{ Stratified by SEX } \\
\hline Female & 1866 & 106319 & 17.55 & 1712 & 90654 & 18.89 & $1.03(0.96-1.10)$ & $1.02(0.95-1.08)$ \\
\hline Male & 2369 & 132259 & 17.91 & 2040 & 108984 & 18.72 & $0.97(0.92-1.03)$ & $0.91 *(0.86-0.97)$ \\
\hline \multicolumn{9}{|c|}{ Stratified by AGE } \\
\hline $0-10$ & 1561 & 46110 & 33.85 & 1691 & 46423 & 36.43 & $1.09 *(1.01-1.16)$ & - \\
\hline $11-20$ & 287 & 22799 & 12.59 & 174 & 21970 & 7.92 & $0.62 *(0.51-0.75)$ & - \\
\hline $21-30$ & 206 & 25423 & 8.10 & 193 & 22582 & 8.55 & $1.04(0.86-1.27)$ & - \\
\hline $31-40$ & 216 & 27674 & 7.81 & 255 & 23773 & 10.73 & $1.34 *(1.12-1.61)$ & - \\
\hline $41-50$ & 325 & 30930 & 10.51 & 305 & 25436 & 11.99 & $1.11(0.94-1.29)$ & - \\
\hline $51-60$ & 379 & 27604 & 13.73 & 301 & 20265 & 14.85 & $1.05(0.90-1.22)$ & - \\
\hline $61-70$ & 446 & 24722 & 18.04 & 385 & 18213 & 21.14 & $1.12(0.98-1.29)$ & - \\
\hline$>70$ & 815 & 33316 & 24.46 & 448 & 20976 & 21.36 & $0.78 *(0.69-0.87)$ & - \\
\hline \multicolumn{9}{|c|}{ Stratified by INCOME } \\
\hline 0 & 2256 & 87760 & 25.71 & 2163 & 80812 & 26.77 & $0.98(093 .-1.04)$ & - \\
\hline$<20000$ & 796 & 51479 & 15.46 & 811 & 54368 & 14.92 & $0.91(0.82-1 . .00)$ & - \\
\hline 20000-39999 & 943 & 72524 & 13.00 & 665 & 51268 & 12.97 & $0.97(0.88-1.07)$ & - \\
\hline$>40000$ & 258 & 26858 & 9.61 & 132 & 13241 & 9.97 & $1.02(0.825-1.26)$ & - \\
\hline \multicolumn{9}{|c|}{ Stratified by LOCATION } \\
\hline $\mathrm{N}$ & 2082 & 106545 & 19.54 & 1815 & 86230 & 21.05 & $1.02(0.96-1.09)$ & - \\
\hline $\mathrm{C}$ & 1047 & 59993 & 17.45 & 1056 & 55292 & 19.10 & $1.03(0.95-1.12)$ & - \\
\hline $\mathrm{S}$ & 958 & 64373 & 14.88 & 744 & 49795 & 14.94 & $0.94(0.85-1.03)$ & - \\
\hline $\mathrm{E}$ & 113 & 5852 & 19.31 & 113 & 6660 & 16.97 & $0.85(0.66-1.11)$ & - \\
\hline $\mathrm{O}$ & 35 & 1815 & 19.29 & 24 & 1662 & 14.44 & $0.74(0.44-1.25)$ & - \\
\hline
\end{tabular}

2 PY: person-years at risk

3 a The incidence is per 1000 person-year

$4{ }^{\mathrm{b}}$ Adjusted for age, sex, income and residence location

$5{ }^{*}$ Significance at 0.05 level 


\section{Figure 1}

\section{Flowchart of study patient selection.}

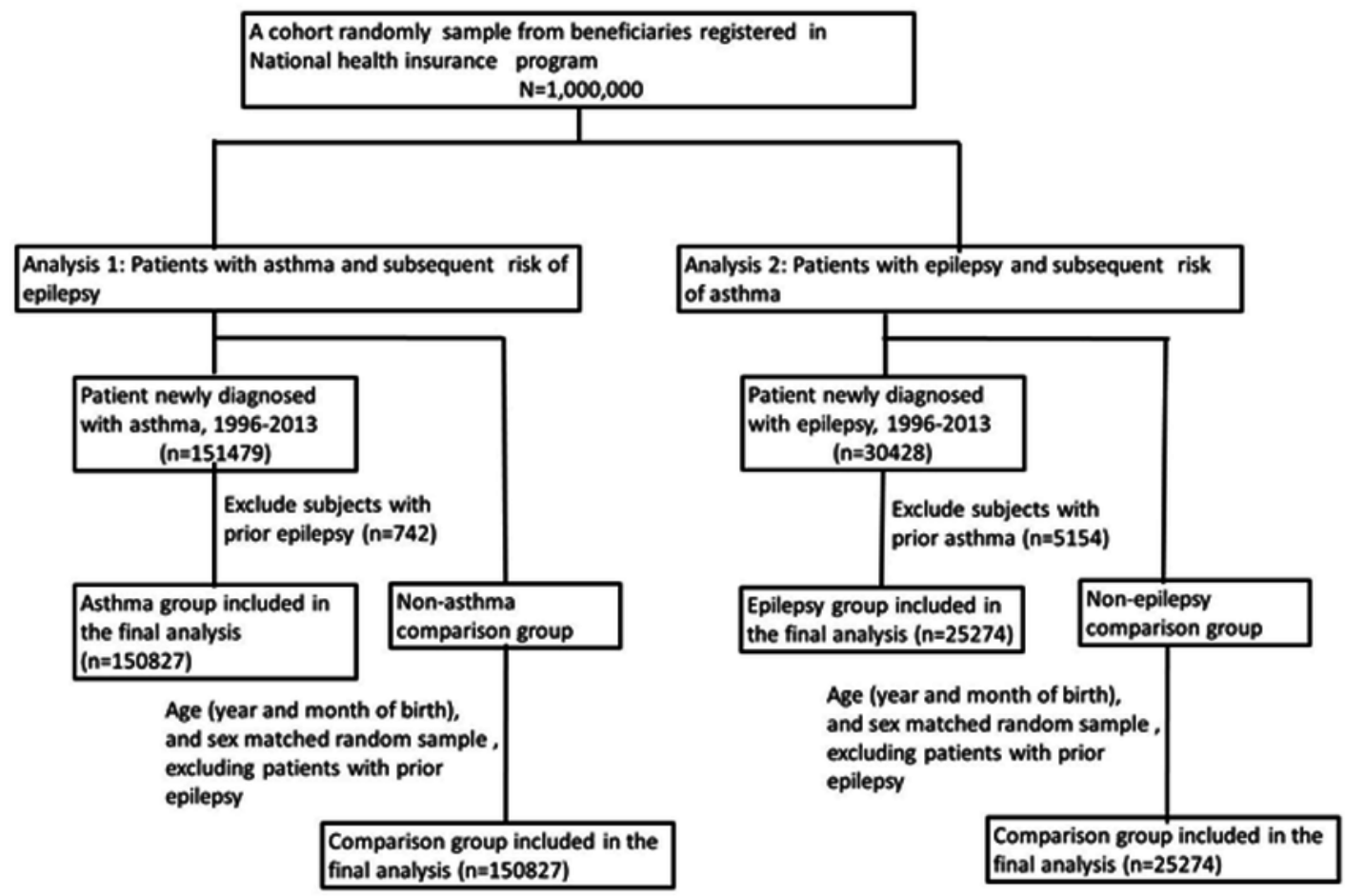


Figure 2

Survival curve of epilepsy development among patients with asthma and the control group.

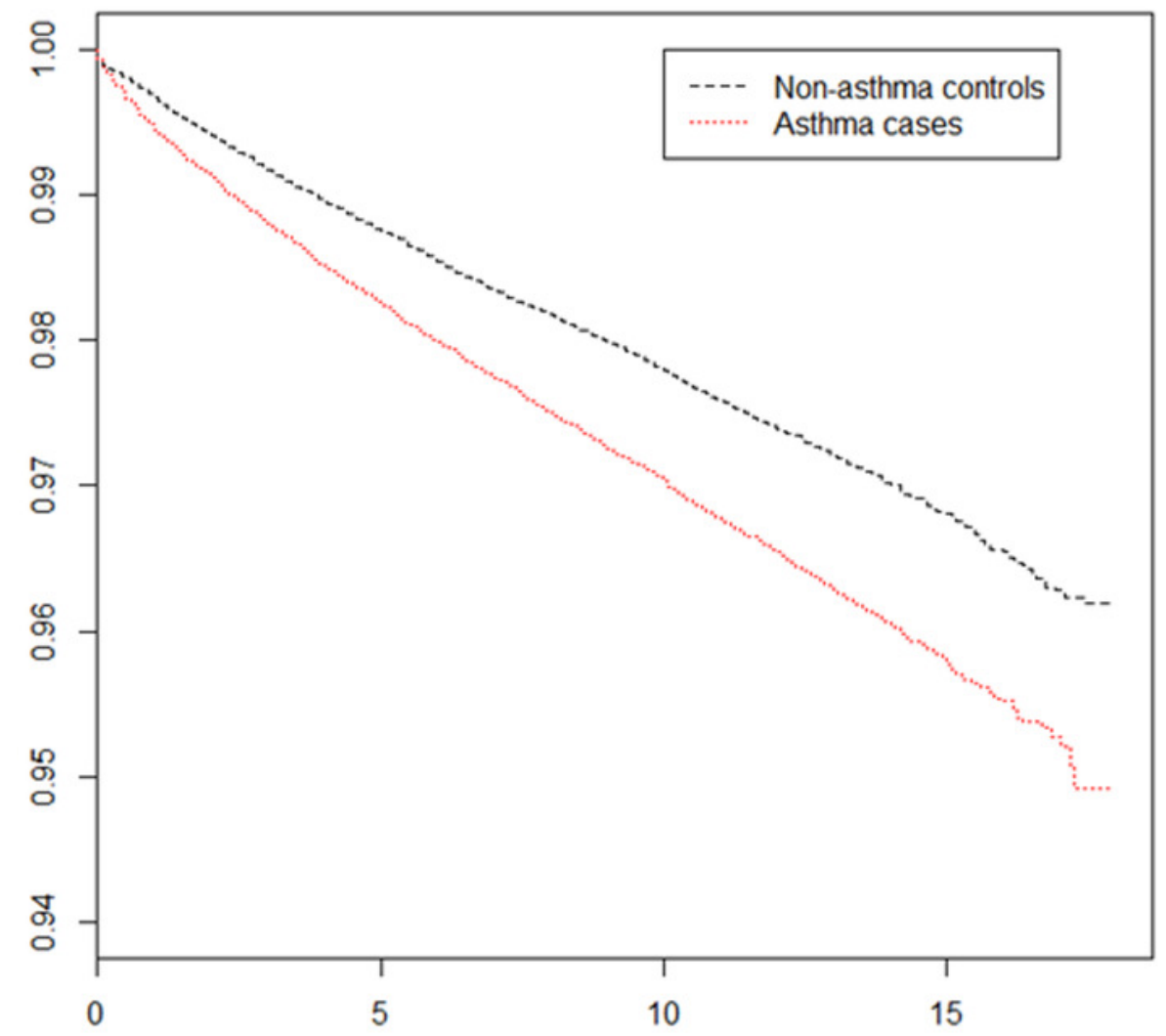


Figure 3

Survival curve of asthma development among patients with epilepsy and the control group.

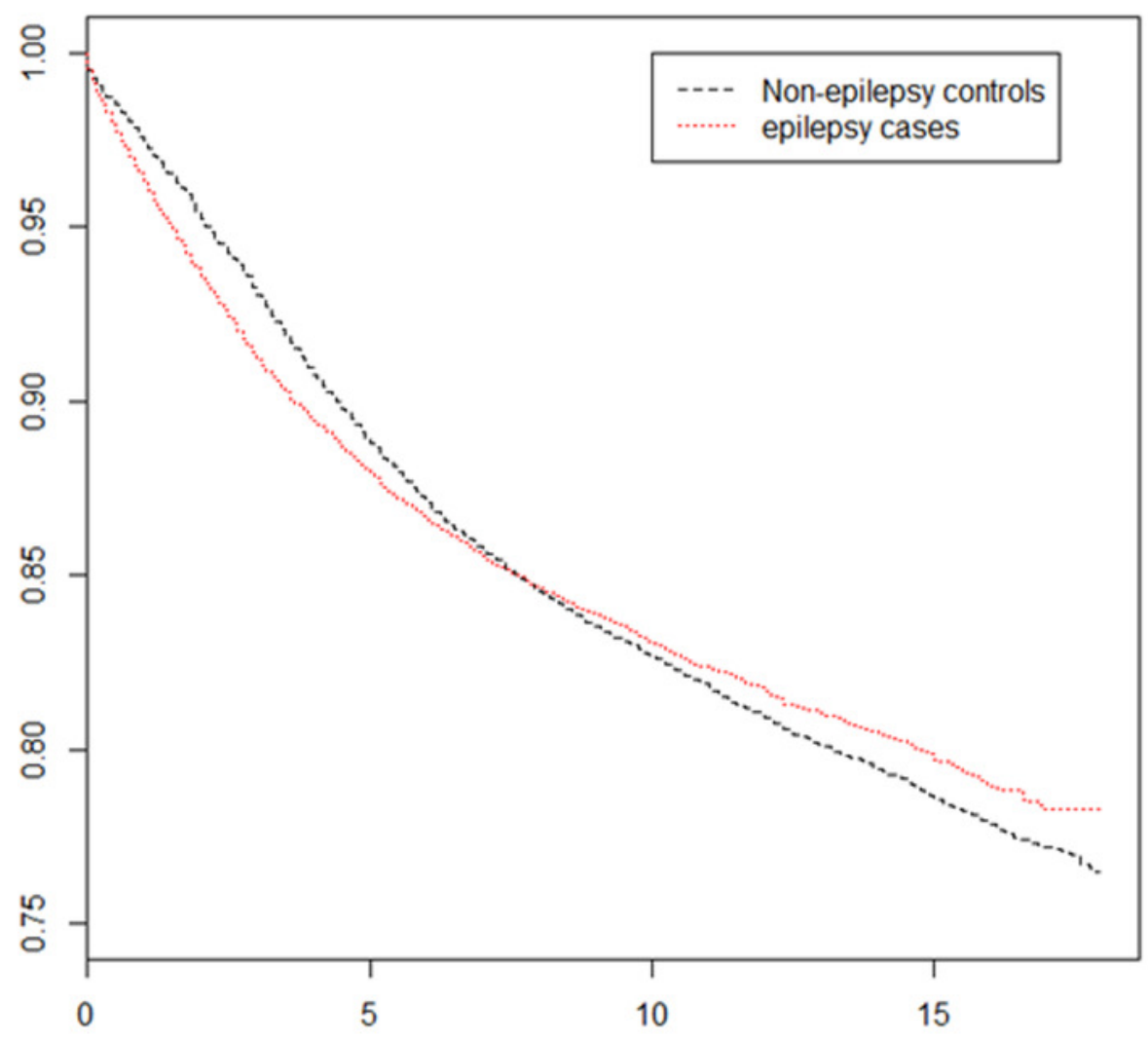


Figure 4

Prevalence of epilepsy and epilepsy with AEDs prescription. (Data reference: Chiang \& Cheng, 2014)

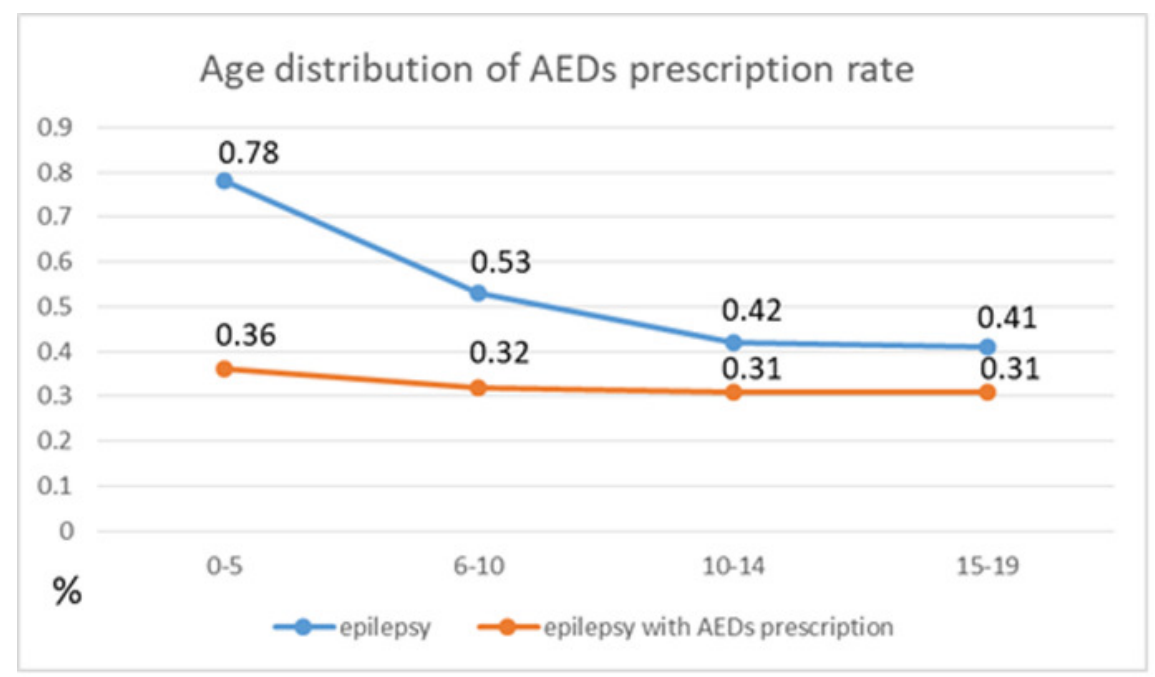

